\title{
Study on the effects of changes in lifestyle of patients with diabetes on glycaemic control before and after the declaration of the state of emergency in Japan
}

\author{
Mio Masuda ${ }^{1} \cdot$ Osamu Tomonaga $^{2}$
}

Received: 4 February 2021 / Accepted: 3 April 2021 / Published online: 20 April 2021

(c) The Japan Diabetes Society 2021

\begin{abstract}
Objective To investigate the actual conditions of changes in lifestyle and treatment status of patients with diabetes before and after the declaration of the state of emergency issued in response to the novel coronavirus.

Methods This study was a collaborative study in two diabetes clinics. A total of 1000 subjects responded to the questionnaire. In addition, data on $\mathrm{HbAlc}$ and body weight before and after the declaration of the state of emergency were collected. Results $\mathrm{HbA1c}$ levels significantly decreased from $7.28 \pm 0.97 \%$ before the declaration of the state of emergency to $7.07 \pm 0.86 \%$ after the declaration $(p<0.001)$. A significant decrease in HbAlc levels was also noted in both T2DM and T1DM. A factorial analysis of the change in HbA1c levels found that a high HbA1c level before the declaration was the most influential factor that made the HbA1c level more likely to decrease, with such factors including a good amount of exercise. A positive correlation with change in body weight was noted. Factors that made the HbA1c level less likely to decrease included stress felt about school closures for children, increased opportunities to eat out, increased food consumption, and refraining from exercise to avoid the "Three Cs" (crowded places, close-contact settings, and confined and enclosed spaces). Conclusion In the absence of serious economic stagnation or completely disrupted distribution, patients are allowed time to do what they like and can probably improve their glycaemic control status if they see this time as an opportunity.
\end{abstract}

Keywords State of emergency $\cdot$ COVID-19 $\cdot$ Lockdown $\cdot$ Stress $\cdot$ Glycaemic control $\cdot$ Diabetes

\section{Introduction}

As of December 27, 2020, COVID-19 has spread to 222 countries around the world and has been reported to have caused more than 1.74 million deaths [1], with its end not yet in sight. In 2020, measures such as lockdowns were implemented in many countries to prevent its spread.

In Japan, a lockdown was not implemented, but a declaration of the state of emergency (hereafter: the declaration) was issued to force the public to refrain from going

Mio Masuda

mail.berryclinic@icloud.com

Berry Clinic, 4-14-10 Ainokawa, Ichikawa, Chiba 299-3235, Japan

2 Diabetes and Lifestyle Center, Tomonaga Clinic, Shinyon Curumu Building 9F, 4-2-23 Shinjuku, Shinjuku-ku, Tokyo 160-0022, Japan out unless absolutely necessary between April 7 and May 25, 2020.

Patients with diabetes have a high risk of developing complications and essentially require regular glycaemic control at medical institutions and other health controls. However, during self-quarantine associated with the declaration, more patients refrained from visiting medical institutions in consideration of a risk of infection, which is expected to have resulted in a decreased opportunity for physical activity changes in dietary content and the opportunity to eat and drink, bringing about effects on body weight and glycaemic control.

Around the start of the lockdowns in many countries, some said that the status of glycaemic control in patients with diabetes would markedly worsen [2,3], and others said that it would not become so serious [4]. So far, these largescale and long-term lockdowns in response to transmittable diseases have not been implemented, and some things will not be known until the data have been verified. 
Reports available to date show results that vary among regions and subjects [5-16]. There is, however, still no report on the actual conditions of changes in lifestyle and treatment status of patients with diabetes before and after the declaration. Therefore, to understand changes in body weight and $\mathrm{HbAlc}$ levels of patients with diabetes under treatment, in addition to their living conditions, a survey was conducted to investigate actual conditions in clinical practice.

\section{Materials and methods}

\section{Study design}

This study was a two-center observational study in Japan (Tokyo and Chiba). Subjects were enrolled between July 10 and September 23, 2020. If too much time has passed, memory of events before and after the declaration is less reliable, so the target number of cases was set at 1000 cases (500 cases at each facility). Patients who met all of the following inclusion criteria were included in this study (the rationales for the criteria are provided in parentheses). No exclusion criteria were used in the study. Subjects were provided with written information on the study, gave written consent, and responded to the patient questionnaire. Data on $\mathrm{HbA} 1 \mathrm{c}$ and body weight before and after the declaration in daily clinical practice were collected. Data after the declaration were represented by data of the date the closest to 3 months after the declaration that were selected from the data at least two but less than 6 months after the declaration.

\section{Inclusion criteria}

(1) Patients who saw a doctor regularly (to examine data before and after the declaration).

(2) Patients at any age and of either sex (to understand actual conditions, regardless of age or sex).

(3) Patients with diabetes (to assess the status of glycaemic control in patients with diabetes).

(4) Patients who provided informed consent for study participation (to conduct the study in accordance with ethical guidelines).

\section{Survey items}

The survey items included: age, sex, occupation, changes before and after the declaration (employment status, dietary life, status of opportunities to eat out, food intake, status of drunkenness, alcohol consumption, frequency of opportunities to drink alcohol, amount of exercise and physical activity, presence or absence in the home of devices to measure body weight, body weight, mental status, status of outpatient visits, medication adherence, presence or absence of perceived effects of self-quarantining associated with the declaration on the management of lifestyle-related diseases, and status of glycaemic control), reason for change in food consumption, reason for change in alcohol consumption, and current method for glycaemic control.

\section{Endpoints}

The primary endpoint was the overall change in $\mathrm{HbAlc} \mathrm{lev-}$ els before and after the declaration. The secondary endpoints included changes in body weight before and after the declaration as well as the responses to the questionnaire. In addition, a subgroup analysis of the change in $\mathrm{HbA1c}$ levels was performed as an exploratory analysis. A multivariate analysis of factors affecting the change in HbAlc levels was also performed. We also compared the results of the two clinics.

\section{Statistical analyses}

Data analysis was performed using $\mathrm{R}$ version 3.5.2 [ $\mathrm{R}$ Foundation for Statistical Computing, Vienna, Austria (https:// www.R-project.org/)]. For data comparison, a Fisher's exact test was used for nominal variables and a Tukey-Kramer test or Student's $t$ test was used for continuous variables. Fisher's exact test or Student's $t$ test was used to evaluate the difference between the two groups. Data with responses answering "unknown" to the questionnaire were excluded from testing. For factorial analysis of the change in $\mathrm{HbA} 1 \mathrm{c}$ levels and change in body weight, items that were found to be significant in a univariate analysis and had missing data from less than 40 subjects were included in multiple regression analysis as explanatory variables. A two-sided significance level of 5\% was applied. The analytical results included in the text are expressed as the mean \pm standard deviation.

\section{Results}

Table 1 shows the subject characteristics. The study population of 1000 subjects consisted of 746 males and 254 females, aged $58.0 \pm 11.6$ years, with $94.6,5.3$, and $0.1 \%$ of the population being represented by patients with type 2 diabetes mellitus (T2DM), type 1 diabetes mellitus (T1DM), and maturity-onset diabetes of the young, respectively. Among the 997 subjects with HbA1c levels available before and after the declaration, there was a significant decrease from $7.28 \pm 0.97 \%$ before the declaration to $7.07 \pm 0.86 \%$ after the declaration, representing a change of $-0.21 \pm 0.64 \%(p<0.001)$ (Table 2). An analysis of 866 subjects, excluding subjects who had changes in medication during the study period, found a 
Table 1 Patient's characteristics

\begin{tabular}{ll}
\hline Item (unit) $(n)$ & Value \\
\hline Age (years) $(n=1000)$ & $58.0 \pm 11.6$ \\
Male/female $(n=1000)$ & $746(74.6 \%)$ \\
& $/ 254$ \\
& $(25.4 \%)$ \\
HbA1c $(\%)(n=997)$ & $7.28 \pm 0.97$ \\
Body weight $($ kg) $(n=999)$ & $69.5 \pm 13.4$ \\
TYPE $(n=1000)$ & \\
Type 1 diabetes mellitus & $53(5.3 \%)$ \\
Type 2 diabetes mellitus & $946(94.6 \%)$ \\
MODY & $1(0.1 \%)$ \\
Complication $(n=1000)$ & \\
Diabetic nephropathy & $193(19.3 \%)$ \\
Diabetic retinopathy & $247(24.7 \%)$ \\
Diabetic neuropathy & $236(23.6 \%)$ \\
Hypertension & $646(64.6 \%)$ \\
Dyslipidemia & $833(83.3 \%)$ \\
Hyperuricemia & $209(20.9 \%)$ \\
Arteriosclerosis obliterans & $16(1.6 \%)$ \\
Cardiovascular disease & $86(8.6 \%)$ \\
Ischemic heart disease & $60(6 \%)$ \\
Cardiac failure & $5(0.5 \%)$ \\
Cerebral stroke & $30(3 \%)$ \\
Pharmacotherapy $(n=1000)$ & \\
Dipeptidyl peptidase- 4 inhibitors & $51(8.1 \%)$ \\
Biguanide & $203(20.3 \%)$ \\
Sulfonylurea & $55(5.5 \%)$ \\
Thiazolidine & $51(5.1 \%)$ \\
$\alpha$-glucosidase inhibitors & \\
Sodium-glucose cotransporter-2 inhibitors & \\
Glinides & $817(71.7 \%)$ \\
Insulin & $67(8.7 \%)$ \\
Glucagon-like peptide-1 receptor agonist & $6(0.6 \%)$ \\
Dietary therapy and exercise therapy alone & $117(11.7 \%)$ \\
\hline
\end{tabular}

significant decrease of $-0.18 \pm 0.65 \%(p<0.001)$, as well as significant decreases of $-0.20 \pm 0.65 \%(p<0.001)$ for T2DM alone and $-0.37 \pm 0.52 \%(p<0.001)$ for T1DM alone. Body weight significantly decreased from $69.50 \pm 13.40 \mathrm{~kg}$ to $69.16 \pm 13.55 \mathrm{~kg}$, representing a change of $-0.35 \pm 1.76 \mathrm{~kg}(p<0.001)$. Major results from the questionnaire are shown in Table 3 , and other results from the patient questionnaire are provided in supplementary material 1 . After the declaration, $75.9 \%$ of patients had decreased opportunities to eat out, $95.7 \%$ used oral drugs or injections as prescribed, $85.6 \%$ took blood glucose measurements as instructed, and $3.4 \%$ experienced a shortage of drugs.

Changes in $\mathrm{HbA} 1 \mathrm{c}$ levels by occupation are provided in supplementary material 2. A significant decrease was noted in all occupations with at least 50 subjects, and a decreasing trend was noted in occupations with fewer subjects.

Eight items showed significant differences in the change in $\mathrm{HbAlc}$ levels among the response options of the questionnaire (Table 4). A test of correlation with changes in $\mathrm{HbA1c}$ levels showed a negative correlation with HbA1c levels before the declaration and positive correlations with changes in body weight and age (supplementary material 3).

A factorial analysis of changes in HbA1c levels found that a high $\mathrm{HbA} 1 \mathrm{c}$ level before the declaration was the most influential factor that made HbA1c levels more likely to decrease, with such factors including a good amount of exercise. A positive correlation with changes in body weight was noted. Factors that made HbA1c levels less likely to decrease included stress felt about school closures for children, increased opportunities to eat out, increased food consumption, and refraining from exercise to avoid the "Three Cs" (Table 5).

The changes in HbA1c levels in Tokyo (Shinjuku) was $-0.22 \pm 0.50 \%$; in Chiba (Ichikawa) the change was $-0.20 \pm 0.76 \%$. There were some difference in patient's characteristics in the two groups, but no significant difference was found in the changes in HbA1c levels $(p=0.551)$ (supplementary materials 4 and 5).

There was no case of hypoglycemia or serious hyperglycemia in study subjects after the declaration.

\section{Discussion}

The evaluation of $\mathrm{HbA1c}$ levels before and after the declaration showed improvement in HbAlc levels in the overall population and in the T2DM and T1DM subpopulations.

There have been reports to date on the status of the management of T2DM during a lockdown. A study of 422 subjects in an urban area in Northern India reported a significant decrease in median $\mathrm{HbA} 1 \mathrm{c}$ levels from $7.8 \%$ before the lockdown to 7.4\% [5]. Our study showed a change in HbA1c levels from $7.28 \pm 0.97 \%$ to $7.07 \pm 0.86 \%$, and this difference in change is considered to be partly due to a lower baseline level than that in the Indian study. This difference is also supported by the multiple regression analysis, which showed that baseline HbA1c levels had the largest effect.

In contrast, a study of 110 subjects in a semi-urban area in Southern India showed no significant change [6], while a study of 101 subjects in a rural area in Turkey showed a worsening, but not significant, trend [7]. The baseline levels in these studies were 8.2\% [6] and 7.67\% [7], respectively, which were higher than that in our study, indicating that baseline levels were not relevant. In the study in Southern India, approximately $10 \%$ of patients had no access to drugs [6], a proportion higher than the $3.4 \%$ in our study. In the Turkish study, the sum of the frequency of exercise of 
Table 2 Changes in each item before and after the declaration of the state of emergency

\begin{tabular}{|c|c|c|c|c|}
\hline & $n$ & Mean & SD & $p$ \\
\hline HbA1c (\%) (before) & 997 & 7.28 & 0.97 & \\
\hline HbA1c (\%) (after) & 997 & 7.07 & 0.86 & $<0.001 *$ \\
\hline$\Delta \mathrm{HbA} 1 \mathrm{c}(\%)$ & 997 & -0.21 & 0.64 & \\
\hline Body weight (kg) (before) & 999 & 69.50 & 13.40 & \\
\hline Body weight (kg) (after) & 999 & 69.16 & 13.55 & $<0.001 *$ \\
\hline$\Delta$ Body weight $(\mathrm{kg})$ & 999 & -0.35 & 1.76 & \\
\hline Number of days working from home per week (before) & 756 & 0.5 & 1.3 & \\
\hline Number of days working from home per week (after) & 756 & 1.8 & 2.0 & $<0.001 *$ \\
\hline$\Delta$ Number of days working from home per week & 756 & 1.3 & 1.9 & \\
\hline Opportunities to eat out per week (before) & 929 & 2.0 & 2.0 & \\
\hline Opportunities to eat out per week (after) & 929 & 1.1 & 1.7 & $<0.001 *$ \\
\hline$\Delta$ Opportunities to eat out per week & 929 & -0.9 & 1.4 & \\
\hline Opportunity for drinking sessions per week (before) & 906 & 0.7 & 1.2 & \\
\hline Opportunities for drinking sessions per week (after) & 906 & 0.3 & 0.9 & $<0.001 *$ \\
\hline$\Delta$ Opportunities for drinking sessions per week & 906 & -0.5 & 0.9 & \\
\hline Time spent watching TV per day (h) (before) & 946 & 2.9 & 2.1 & \\
\hline Time spent watching TV per day (h) (after) & 946 & 3.5 & 2.4 & $<0.001 *$ \\
\hline$\Delta$ Time spent watching $\mathrm{TV}$ per day (h) & 946 & 0.6 & 1.4 & \\
\hline Sleep time per day (h) (before) & 936 & 6.2 & 1.0 & \\
\hline Sleep time per day (h) (after) & 936 & 6.3 & 1.1 & $<0.001 *$ \\
\hline$\Delta$ Sleep time per day (h) & 936 & 0.1 & 0.7 & \\
\hline
\end{tabular}

${ }^{*} p<0.001$, vs before the declaration, paired $t$ test "never" and "rarely" was $69.2 \%$ [7], while a smaller proportion of subjects, $43.3 \%$, achieved not more than $50 \%$ of the exercise goal in our study. In addition, this study, taken in conjunction with these studies, suggests that the status of management is better in urban areas and tends to be poor in rural areas.

An Indian study of 146 patients with T2DM showed that some patients were transported to a hospital with hypoglycemia due to poor glycaemic control associated with the lockdown. In particular, a combination of metformin and a sulfonylurea (SU) was commonly used, by $65.75 \%$ of patients, and insulin was used by $33.56 \%$ of patients [8]. Our study demonstrated that no patients had experienced hypoglycemia. This result may be due to efforts to avoid combinations of drugs that can cause severe hypoglycemia. We paid particular attention to the combination of SU with other drugs. DPP4 inhibitors, which exhibit a drug efficacy in a blood glucose-dependent manner, are used in Japan more than SU is and are less likely to cause hypoglycemia. In our study, insulin or GLP-1 receptor agonists were used by about $25 \%$ of patients, of whom none experienced hypoglycemia, probably because daily education kept them informed about their physical conditions and the usage of drugs.

For T1DM, there are many reports of improved glycaemic control. Improvement has been reported in many countries, such as India [9], the UK [10, 11], and Spain [12-14]. In contrast, a report of 50 patients in Rome, Italy, indicated that glycaemic control was markedly worsened during the lockdown [15], and a study of 52 patients in Rohtak, an industrial city in Northern India, reported an increase from $8.8 \pm 1.3 \%$ before the lockdown to $10.0 \pm 1.5 \%$ after the lockdown [16].

A report from Italy [15] indicated that the development of problems related to an unstable employment situation was a major determinant of an increase in changes in glucose. A proportion of individuals who were unemployed or suspended from employment combined was $32 \%$, suggesting that there was stress deriving from such situations. In an Indian study [16], the majority of the study population consisted of minors, indicating a different profile from that of other studies. Aggravating factors included a limited stock of drugs in rural and semi-urban areas, restricted transport during the lockdown period, and a low socio-economic status of parents (65.4\% of parents) or the presence of parents who could not work during the lockdown period, with only $25 \%$ of parents receiving a salary on a regular basis during the lockdown. In contrast, a study at Jehangir hospital in Pune, a city in western central India was conducted with subjects aged 20 or younger, but showed that HbA1c levels were improved [9]. Differences in transportation and economic aspects between urban and rural areas became evident. As of September 2020, the end of this study, the number of wholly unemployed persons was 2.1 million in Japan, which was 1.25 times that in the same month in 2019 [17]. Although the economy deteriorated in Japan, economic deterioration was 
Table 3 Excerpts from questionnaire responses

\begin{tabular}{|c|c|c|c|c|}
\hline Opportunities to eat out & $\begin{array}{l}\text { Increased } \\
18(1.8 \%)\end{array}$ & $\begin{array}{l}\text { Decreased } \\
751(75.9 \%)\end{array}$ & $\begin{array}{l}\text { Unchanged } \\
220(22.2 \%)\end{array}$ & \\
\hline Food intake & $\begin{array}{l}\text { Increased } \\
114(11.6 \%)\end{array}$ & $\begin{array}{l}\text { Decreased } \\
220(22.3 \%)\end{array}$ & $\begin{array}{l}\text { Unchanged } \\
653(66.2 \%)\end{array}$ & \\
\hline Alcohol consumption & $\begin{array}{l}\text { Increased } \\
68(7.3 \%)\end{array}$ & $\begin{array}{l}\text { Decreased } \\
315(33.9 \%)\end{array}$ & $\begin{array}{l}\text { Unchanged } \\
546(58.8 \%)\end{array}$ & \\
\hline Opportunities to drink alcohol & $\begin{array}{l}\text { Increased } \\
37(4 \%)\end{array}$ & $\begin{array}{l}\text { Decreased } \\
525(56.7 \%)\end{array}$ & $\begin{array}{l}\text { Unchanged } \\
364(39.3 \%)\end{array}$ & \\
\hline Amount of exercise and physical activity & $\begin{array}{l}\text { Increased } \\
135(13.7 \%)\end{array}$ & $\begin{array}{l}\text { Decreased } \\
544(55 \%)\end{array}$ & $\begin{array}{l}\text { Unchanged } \\
310(31.3 \%)\end{array}$ & \\
\hline $\begin{array}{l}\text { Refraining from exercise to avoid three Cs } \\
\text { (crowded places, close-contact settings, } \\
\text { and confined and enclosed spaces) }\end{array}$ & $\begin{array}{l}\text { Not applicable } \\
822(82.2 \%)\end{array}$ & $\begin{array}{l}\text { Applicable } \\
178(17.8 \%)\end{array}$ & & \\
\hline Anxiety and stress & $\begin{array}{l}\text { Increased } \\
388(40.8 \%)\end{array}$ & $\begin{array}{l}\text { Decreased } \\
39(4.1 \%)\end{array}$ & $\begin{array}{l}\text { Unchanged } \\
523(55.1 \%)\end{array}$ & \\
\hline Regarding outpatient visits & $\begin{array}{l}\text { Continued } \\
852(89 \%)\end{array}$ & $\begin{array}{l}\text { Suspended } \\
27(2.8 \%)\end{array}$ & $\begin{array}{l}\text { Drug therapy } \\
\text { alone contin- } \\
\text { ued } \\
78(8.2 \%)\end{array}$ & \\
\hline Drugs & $\begin{array}{l}\text { Continued as prescribed } \\
921(97.3 \%)\end{array}$ & $\begin{array}{l}\text { Adjusted based on the patient's own judg- } \\
\text { ment } \\
26(2.7 \%)\end{array}$ & & \\
\hline For lifestyle management & $\begin{array}{l}\text { Favorable } \\
167(17.4 \%)\end{array}$ & $\begin{array}{l}\text { Unfavorable } \\
217(22.6 \%)\end{array}$ & $\begin{array}{l}\text { No opinion } \\
575(60 \%)\end{array}$ & \\
\hline Increased frequency of work from home & $\begin{array}{l}\text { Not applicable } \\
672(67.2 \%)\end{array}$ & $\begin{array}{l}\text { Applicable } \\
328(32.8 \%)\end{array}$ & & \\
\hline Sedentary behaviour & Continued for at least $30 \mathrm{~min}$ & $\begin{array}{l}\text { Suspended every } 30 \text { min and moved the } \\
\text { body }\end{array}$ & & $p$ \\
\hline Before the declaration & $701(82.5 \%)$ & $149(17.5 \%)$ & & 0.356 \\
\hline After the declaration & $678(84.2 \%)$ & $127(15.8 \%)$ & & \\
\hline Regarding oral drugs or injections & Adhered to the instructions & $\begin{array}{l}\text { Adjusted based on the patient's own judg- } \\
\text { ment }\end{array}$ & Used irregularly & $p$ \\
\hline Before the declaration & $910(95.6 \%)$ & $30(3.2 \%)$ & $12(1.3 \%)$ & 0.293 \\
\hline After the declaration & $912(95.7 \%)$ & $35(3.7 \%)$ & $6(0.6 \%)$ & \\
\hline Frequency of blood glucose measurement & Adhered to the instructions & $\begin{array}{l}\text { Adjusted based on the patient's own judg- } \\
\text { ment }\end{array}$ & Used irregularly & $p$ \\
\hline Before the declaration & $454(84.7 \%)$ & $31(5.8 \%)$ & $51(9.5 \%)$ & 0.892 \\
\hline After the declaration & $465(85.6 \%)$ & $31(5.7 \%)$ & $47(8.7 \%)$ & \\
\hline Shortage of drugs & Yes & No & & $p$ \\
\hline Before the declaration & $21(2.2 \%)$ & $936(97.8 \%)$ & & 0.128 \\
\hline After the declaration & $33(3.4 \%)$ & $926(96.6 \%)$ & & \\
\hline
\end{tabular}

N.S., Fisher's exact test

more marked in India, where the unemployment increased from $8.74 \%$ in March 2020 to $23.52 \%$ in April before further increasing to $27.11 \%$ in May [18]. The rate subsequently returned to the level before the coronavirus crisis, while in Japan, the amplitude of changes in employment was smaller than in developing countries, suggesting that effects originating from economic aspects were small.

Our study suggests that, unless the employment situation or distribution significantly deteriorates, changes in lifestyles associated with the declaration, such as self-quarantine measures and working from home, does not significantly worsen the glycaemic control of many patients with diabetes, but rather may provide a favorable opportunity for improvement for individuals who utilize the time allowed effectively.

Individual subgroup analyses showed that decreases in HbA1c levels were greater in the groups of patients who took body weight measurements, performed self-monitoring of blood glucose, had no increase in food consumption, and had increased amounts of exercise and physical activity than the groups of patients who did not take body weight measurements, did not perform self-monitoring of blood glucose, had increases in food consumption, and had no increase in 
Table 4 Results of responses to the questionnaire and changes in HbA1c levels

\begin{tabular}{|c|c|c|c|c|c|c|c|}
\hline & \multirow[t]{2}{*}{$n$} & \multirow[t]{2}{*}{ Mean } & \multirow[t]{2}{*}{ SD } & \multirow{2}{*}{$\begin{array}{l}\text { Student's } t \text { test } \\
p \text { (A vs B) }\end{array}$} & \multicolumn{3}{|c|}{ Tukey-Kramer test } \\
\hline & & & & & $p(\mathrm{~A}$ vs $\mathrm{B})$ & $p(\mathrm{~A}$ vs $\mathrm{C})$ & $p(\mathrm{~B}$ vs $\mathrm{C})$ \\
\hline \multicolumn{8}{|c|}{$\begin{array}{l}\text { Refraining from exercise to avoid three Cs (crowded places, close-contact settings, and confined and } \\
\text { enclosed spaces) }\end{array}$} \\
\hline A. Applicable & 178 & -0.12 & 0.59 & $0.049^{*}$ & & & \\
\hline B. Not applicable & 819 & -0.23 & 0.65 & & & & \\
\hline \multicolumn{8}{|l|}{ Body weight measurement } \\
\hline A. Took measurements & 711 & -0.24 & 0.58 & $0.029^{*}$ & & & \\
\hline B. Did not take measurements & 235 & -0.13 & 0.80 & & & & \\
\hline \multicolumn{8}{|l|}{ School closure for children } \\
\hline A. Applicable & 40 & 0.00 & 0.82 & $0.032 *$ & & & \\
\hline B. Not applicable & 957 & -0.22 & 0.63 & & & & \\
\hline \multicolumn{8}{|c|}{ Self-monitoring of blood glucose } \\
\hline A. Perform & 224 & -0.29 & 0.79 & $0.019 *$ & & & \\
\hline B. Not perform & 729 & -0.18 & 0.58 & & & & \\
\hline \multicolumn{8}{|l|}{ Opportunities to eat out } \\
\hline A. Increased & 18 & 0.24 & 1.01 & & $0.006^{*}$ & $0.024 *$ & 0.450 \\
\hline B. Decreased & 748 & -0.23 & 0.64 & & & & \\
\hline C. Unchanged & 220 & -0.17 & 0.61 & & & & \\
\hline \multicolumn{8}{|l|}{ Food intake } \\
\hline A. Increased & 113 & 0.00 & 0.73 & & $<0.001 *$ & $0.003^{*}$ & 0.059 \\
\hline B. Decreased & 220 & -0.31 & 0.70 & & & & \\
\hline C. Unchanged & 651 & -0.21 & 0.56 & & & & \\
\hline \multicolumn{8}{|c|}{ Amount of exercise and physical activity } \\
\hline A. Increased & 134 & -0.39 & 0.76 & & $<0.001^{*}$ & $0.018^{*}$ & 0.495 \\
\hline B. Decreased & 543 & -0.16 & 0.64 & & & & \\
\hline C. Unchanged & 309 & -0.21 & 0.58 & & & & \\
\hline \multicolumn{8}{|l|}{ Regarding lifestyle management } \\
\hline A. Favorable & 167 & -0.41 & 0.74 & & $<0.001 *$ & $0.002 *$ & $<0.001^{*}$ \\
\hline B. Unfavorable & 216 & 0.01 & 0.58 & & & & \\
\hline C. No opinion & 573 & -0.23 & 0.56 & & & & \\
\hline
\end{tabular}

${ }^{*} p<0.05$, Student's $t$ test or Tukey-Kramer test

Table 5 Factorial analysis of the changes in HbA1c levels

\begin{tabular}{|c|c|c|c|c|}
\hline Variables & $\begin{array}{l}\text { Partial regression coef- } \\
\text { ficient }\end{array}$ & Standard error & $\begin{array}{l}\text { Standard partial regression } \\
\text { coefficient }\end{array}$ & $p$ \\
\hline HbA1c levels (\%) (before the declaration) & -0.284 & 0.018 & -0.441 & $<0.001 *$ \\
\hline$\Delta$ Body weight (kg) & 0.053 & 0.010 & 0.154 & $<0.001 *$ \\
\hline Stress felt about school closure for children & 0.252 & 0.088 & 0.079 & $0.004 *$ \\
\hline Opportunities to eat out $\mathrm{t}^{\mathrm{a}}$ & 0.109 & 0.036 & 0.085 & $0.002 *$ \\
\hline Food intake $^{\mathrm{a}}$ & 0.108 & 0.030 & 0.101 & $<0.001 *$ \\
\hline Age (years) & 0.001 & 0.001 & 0.020 & 0.471 \\
\hline Status of exercise (before the declaration) ${ }^{b}$ & 0.054 & 0.016 & 0.097 & $0.001 *$ \\
\hline
\end{tabular}

$* p<0.05$, multiple regression analysis

ancrease: 1, unchanged: 0, decreased: -1

${ }^{b}$ Variables were included after conversion as follows: $100 \%$ achievement: 1, 80\% achievement: 2, 50\% achievement: 3, and lower level of achievement: 4 
amount of exercise and physical activity. In addition, patients who reported that this declaration benefited their lifestyle management showed significant improvement compared with those who did not. These results suggest that patient awareness affects the status of glycaemic control. Other comparative studies before and after lockdowns showed that patients showing improvement were those who were willing to make regular visits to a diabetes clinic and were familiar with recommended lifestyles and target blood glucose levels [5]. However, steady efforts for education by experts in medical institutions are essential for raising patient awareness of glycaemic control and sustaining improvement in diet and exercise habits. Education by registered dietitians is effective for the practice of dietary therapy $[19,20]$. Both sites in which this study was conducted provided education by certified diabetes educators and registered dietitians, which is likely to have been beneficial. In this study, we compared the changes in $\mathrm{HbAlc}$ between the two sites, but no significant difference was observed. As of September 23, 2020 , at the end of the study, the cumulative population ratio of infected people in Tokyo was $0.17 \%(24,448 / 13,981,782)$ $[21,22]$; in Chiba prefecture, $0.06 \%(3,675 / 6,282,811)[23$, 24], a difference of about three times. In addition, the complications of the subjects and the usage rate of therapeutic drugs were different. However, the facility in Ichikawa City, Chiba Prefecture, is located in front of the station, it takes about 30 min to commute to Tokyo, and the population density is at least half of Tokyo's. In addition, both sites are clinics specializing in diabetes that provide team medical care, the patient's continuation rate of medication was high, and outpatient visits were not severely delayed. We believe these are the factors that brought about similar results.

Inadequate knowledge of diabetes is associated with reduced medication adherence $[25,26]$. Receipt of information from healthcare providers is associated with enhanced compliance with diabetic treatments [27], suggesting the importance of clinicians who arrange time for providing education to patients. This study showed that $95.7 \%$ of patients adhered to instructions for medication and injection even after the declaration, suggesting that patients were routinely well educated. A survey on medication adherence in patients with T2DM reported that a stronger tendency toward pessimism or worry about future problems led to poor medication adherence, while a stronger tendency to control activities according to purposes or values led to favorable medication adherence [28]. Even given that the rate of poor medication adherence to diabetes medication in Japan is approximately $30 \%$ [29], this adherence rate in the coronavirus crisis is the result of medicine managed by a team. The results of this study suggest that the declaration issued in Japan did not significantly affect medication adherence when patients were well educated in medical institutions specialized in diabetes.
Interestingly, patients who felt stress about the closure of children's schools showed poorer control of HbAlc levels than those who felt no such stress. A comparative study before and after the lockdown reported that the majority of study participants with increased mental stress maintained unhealthy dietary patterns [6]. Our study showed that a certain number of patients had increased food intake and alcohol consumption, suggesting that stress is linked to disturbed dietary habits. However, this study analyzed changes in HbAlc levels by type of stress and demonstrated that only stress felt about the closure of children's schools led to a significant difference in responses. Only this item showed a significant difference, probably due to the type of stress which would have not been felt normally.

In this study, there was no significant difference in changes in $\mathrm{HbA} 1 \mathrm{c}$ levels for the broad category of questions about increases and decreases in anxiety and stress. A report described the correlation of depression or depressive symptoms with HbA1c levels in T2DM [30, 31]. There was also a report indicating that anxiety in particular was most strongly correlated with HbA1c level, followed by depression and stress [32], but individual analyses of anxiety and stress may provide a factorial analysis.

There is a report that blood glucose levels fluctuate with the season and $\mathrm{HbA} 1 \mathrm{c}$ levels are high in the winter and low in the summer [33-37]. The same has been described in reports on drug effectiveness [38, 39]. It is still possible that the season from April to July has an effect. However, reports on worsening conditions have emerged from countries in the northern hemisphere $[7,15,16]$, suggesting that it is impossible for seasonal fluctuation to be the only contributing factor.

A lockdown for an unknown virus may be required in the future. However, in the absence of serious economic stagnation or completely disrupted distribution, glycaemic control can be maintained by encouraging patients to receive dietary and exercise therapies on a routine basis, gaining a deeper understanding of diabetes, and ensuring team medicine to raise patients' awareness.

\section{Limitations}

This study has several limitations. It was conducted in Tokyo and its bed town, Ichikawa, Chiba. Therefore, its subject population was limited to patients in urban areas, and the results cannot be reliably generalized throughout Japan. The lockdown was not complete, and the self-quarantine period requested by the government was also different from that in other countries. The questionnaire used was created independently and not a universal standard. As not all patients in the sites were included in the study, the actual conditions of patients who could not provide informed consent, including 
those who did not go to hospitals or were transferred to other hospitals, could not be understood.

\section{Conclusion}

A comparison before and after the declaration of the state of emergency in Japan showed a significant decrease in HbA1c levels in both patients with T2DM and patients with T1DM. In the absence of serious economic stagnation or completely disrupted distribution, patients are allowed time to do what they like and can probably improve their glycaemic control status if they see this time as an opportunity. Even if patients do not see this time as an opportunity, glycaemic control can be maintained by encouraging patients to receive dietary and exercise therapies routinely, gaining a deeper understanding of diabetes, and ensuring team medicine to raise patient awareness.

Supplementary Information The online version contains supplementary material available at https://doi.org/10.1007/s13340-021-00505-6.

Acknowledgements We would like to thank the physicians and staff of the Berry Clinic and Tomonaga Clinic involved in the research and the patients participating in this study. We would like to express our sincere gratitude to Shido Inc. for conducting the data collection and analyses.

Author contributions Conceived and designed the experiments: MM. Enrolled patients: MM and OT. Analyzed the data: MM. Wrote the first draft of the manuscript: MM. Contributed to the writing of the manuscript: MM and OT. All the authors agreed with the manuscript's results and conclusions. All the authors have read, and confirm that they meet, ICMJE criteria for authorship.

Funding This study was self-funded.

Data availability The biochemical data used to support the findings of this study are available from the corresponding author upon request.

\section{Declarations}

Conflict of interest The authors declare no conflicts of interest.

Ethic approval and consent to participate This study was registered with the Clinical Trials Registry (https://www.umin.ac.jp/; UMIN000041065) and was undertaken in accordance with the study protocol, the Declaration of Helsinki and the Ethical Guidelines for Clinical Studies of the Japanese Ministry of Health, Labor, and Welfare. This study was approved by the ethics committee at the Diabetes and Lifestyle Center, Tomonaga Clinic (July 10, 2020). Approval Number: 20200709. The all participants provided written informed consent before participation.

\section{References}

1. World Health Organization. Coronavirus disease (COVID-19) pandemic. https://www.who.int/emergencies/diseases/novel-coron avirus-2019. Accessed 27 Dec 2020
2. Ghosal S, Sinha B, Majumder M, et al. Estimation of effects of nationwide lockdown for containing coronavirus infection on worsening of glycosylated haemoglobin and increase in diabetesrelated complications: a simulation model using multivariate regression analysis. Diabetes Metab Syndr. 2020;14(4):319-23. https://doi.org/10.1016/j.dsx.2020.03.014.

3. Ghosal S. Reply to letter to the editor regarding article: Estimation of effects of nationwide lockdown for containing coronavirus infection on worsening of glycosylated haemoglobin and increase in diabetes-related complications: a simulation model using multivariate regression analysis (Ghosal et al.). Diabetes Metab Syndr. 2020;14(4):449. https://doi.org/10.1016/j.dsx.2020.04.028.

4. Kumar A, Arora A, Sharma P. Letter to the editor regarding article: estimation of effects of nationwide lockdown for containing coronavirus infection on worsening of glycosylated haemoglobin and increase in diabetes-related complications: a simulation model using multivariate regression analysis (Ghoshal et al.). Diabetes Metab Syndr. 2020;14(4):383. https://doi.org/10.1016/j.dsx.2020. 04.027.

5. Rastogi A, Hiteshi P, Bhansali A. Improved glycemic control amongst people with long-standing diabetes during COVID-19 lockdown: a prospective, observational, nested cohort study. Int J Diabetes Dev Ctries. 2020;21:1-6. https://doi.org/10.1007/ s13410-020-00880-x.

6. Sankar P, Ahmed WN, Koshy VM, et al. Effects of COVID-19 lockdown on type 2 diabetes, lifestyle and psychosocial health: a hospital-based cross-sectional survey from south India. Diabetes Metab Syndr. 2020;14(6):1815-9. https://doi.org/10.1016/j.dsx. 2020.09.005.

7. Önmez A, Gamsızkan Z, Özdemir Ş, et al. The effect of COVID19 lockdown on glycemic control in patients with type 2 diabetes mellitus in Turkey. Diabetes Metab Syndr. 2020;14(6):1963-6. https://doi.org/10.1016/j.dsx.2020.10.007.

8. Shah K, Tiwaskar M, Chawla P, et al. Hypoglycemia at the time of COVID-19 pandemic. Diabetes Metab Syndr. 2020;14(5):1143-6. https://doi.org/10.1016/j.dsx.2020.07.003.

9. Shah N, Karguppikar M, Bhor S, et al. Impact of lockdown for COVID-19 pandemic in Indian children and youth with type 1 diabetes from different socio-economic classes. J Pediatr Endocrinol Metab. 2020. https://doi.org/10.1515/jpem-2020-0460.

10. Prabhu Navis J, Leelarathna L, Mubita W, et al. Impact of COVID19 lockdown on flash and real-time glucose sensor users with type 1 diabetes in England. Acta Diabetol. 2020;16:1-7. https://doi. org/10.1007/s00592-020-01614-5.

11. Dover AR, Ritchie SA, McKnight JA, et al. Assessment of the effect of the COVID-19 lockdown on glycaemic control in people with type 1 diabetes using flash glucose monitoring. Diabet Med. 2020;2:e14374. https://doi.org/10.1111/dme.14374.

12. Viñals $C$, Mesa A, Roca D, et al. Management of glucose profile throughout strict COVID-19 lockdown by patients with type 1 diabetes prone to hypoglycaemia using sensor-augmented pump. Acta Diabetol. 2020;30:1-6. https://doi.org/10.1007/ s00592-020-01625-2.

13. Fernández E, Cortazar A, Bellido V. Impact of COVID-19 lockdown on glycemic control in patients with type 1 diabetes. Diabetes Res Clin Pract. 2020;166:108348. https://doi.org/10.1016/j. diabres.2020.108348.

14. Pla B, Arranz A, Knott C, et al. Impact of COVID-19 lockdown on glycemic control in adults with type 1 diabetes mellitus. J Endocr Soc. 2020;4(12):bvaa149. https://doi.org/10.1210/jendso/bvaa1 49 (eCollection 2020 Dec 1).

15. Barchetta I, Cimini FA, Bertoccini L, et al. Effects of work status changes and perceived stress on glycaemic control in individuals with type 1 diabetes during COVID-19 lockdown in Italy. Diabetes Res Clin Pract. 2020;16(170):108513. https://doi.org/10. 1016/j.diabres.2020.108513. 
16. Verma A, Rajput R, Verma S, et al. Impact of lockdown in COVID 19 on glycemic control in patients with type 1 diabetes mellitus. Diabetes Metab Syndr. 2020;14(5):1213-6. https://doi.org/10. 1016/j.dsx.2020.07.016.

17. Labor force survey Ministry of Internal Affairs and Communications. Labor force survey. https://www.stat.go.jp/data/roudou/ rireki/tsuki/pdf/202009.pdf. Accessed 27 Dec 2020

18. Centre for Monitoring Indian Economy. Unemployment rate in India. https://unemploymentinindia.cmie.com/. Accessed 27 Dec 2020

19. Møller G, Andersen HK, Snorgaard O. A systematic review and meta-analysis of nutrition therapy compared with dietary advice in patients with type 2 diabetes. Am J Clin Nutr. 2017;106(6):1394400. https://doi.org/10.3945/ajcn.116.139626.

20. Huang MC, Hsu CC, Wang HS, et al. Prospective randomized controlled trial to evaluate effectiveness of registered dietitian-led diabetes management on glycemic and diet control in a primary care setting in Taiwan. Diabetes Care. 2010;33(2):233-9. https:// doi.org/10.2337/dc09-1092.

21. Japan Broadcasting Corporation. Data of COVID-19 in Tokyo. https://www3.nhk.or.jp/news/special/coronavirus/data/pref/tokyo. html. Accessed 8 Mar 2021

22. Statistics Division, Bureau of General Affairs. Population in Tokyo. https://www.toukei.metro.tokyo.lg.jp/jsuikei/js-index2. htm. Accessed 8 Mar 2021

23. Japan Broadcasting Corporation. Data of COVID-19 in Chiba. https://www3.nhk.or.jp/news/special/coronavirus/data/pref/chiba. html. Accessed 8 Mar 2021

24. Chiba Prefecture Govermment. Monthly resident census in Chiba Prefecture. https://www.pref.chiba.lg.jp/toukei/toukeidata/joujuu/ geppou/2020/index.html. Accessed 8 Mar 2021

25. Shams N, Amjad S, Kumar N, et al. Drug non-adherence in type 2 diabetes mellitus; predictors and associations. J Ayub Med Coll Abbottabad. 2016;28(2):302-7.

26. Kassahun T, Gesesew H, Mwanri L, et al. Diabetes related knowledge, self-care behaviours and adherence to medications among diabetic patients in southwest Ethiopia: a cross-sectional survey. BMC Endocr Disord. 2016;16(1):28. https://doi.org/10.1186/ s12902-016-0114-x.

27. Larkin AT, Hoffman C, Stevens A, et al. Determinants of adherence to diabetes treatment. J Diabetes. 2015;7(6):864-71. https:// doi.org/10.1111/1753-0407.12264.

28. Tominaga Y, Aomori T, Hayakawa T, et al. Possible associations of personality traits representing harm avoidance and self-directedness with medication adherence in Japanese patients with type 2 diabetes. J Pharm Health Care Sci. 2018;4:16. https://doi.org/ 10.1186/s40780-018-0112-4 (eCollection 2018).

29. Tominaga Y, Aomori T, Hayakawa T, et al. Relationship between medication adherence and glycemic control in Japanese patients with type 2 diabetes. Pharmazie. 2018;73(10):609-12. https://doi. org/10.1691/ph.2018.8587.

30. Schmitz N, Gariépy G, Smith KJ, et al. Longitudinal relationships between depression and functioning in people with type 2 diabetes. Ann Behav Med. 2014;47:172-9. https://doi.org/10.1007/ s12160-013-9534-2

31. Schmitz N, Deschênes SS, Burns RJ et al. Depressive symptoms and glycated haemoglobin A1c: a reciprocal relationship in a prospective cohort study. Psych Med. 2016;46:945-55. https://doi. org/10.1017/S0033291715002445

32. Chlebowy DO, Batscha C, Kubiak N, et al. Relationships of depression, anxiety, and stress with adherence to self-management behaviors and diabetes measures in African American adults with type 2 diabetes. J Racial Ethn Health Disparities. 2019;6(1):71-6. https://doi.org/10.1007/s40615-018-0500-3.

33. Sakura H, Tanaka Y, Iwamoto Y. Seasonal fluctuations of glycated hemoglobin levels in Japanese diabetic patients. Diabetes Res Clin Pract. 2010;88:65-70. https://doi.org/10.1016/j.diabres.2009.12. 011

34. Iwao T, Sakai K, Ando E. Seasonal fluctuations of glycated hemoglobin levels in Japanese diabetic patients: effect of diet and physical activity. Diabetol Int. 2013;4:173-8. https://doi.org/10.1007/ s13340-013-0112-4

35. Iwata $\mathrm{K}$, Iwasa $\mathrm{M}, \mathrm{Nakatani} \mathrm{T}$, et al. Seasonal variation in visceral fat and blood $\mathrm{HbAlc}$ in people with type 2 diabetes. Diabetes Res Clin Pract. 2012;96:e53-4. https://doi.org/10.1016/j.diabres.2011. 10.036

36. Zhang L, Li W, Xian T, et al. Seasonal variations of hemoglobin A1c in residents of Beijing, China. Int Clin Exp Pathol. 2016;9:9429-35.

37. Pereira MT, Lira D, Bacelar C, et al. Seasonal variation of haemoglobin A1c in a Portuguese adult population. Arch Endocrinol Metab. 2015;59:231-5. https://doi.org/10.1590/2359-3997000000 043

38. Sakura H, Hashimoto N, Sasamoto K, et al. Analysis of the effect of seasonal administration on the efficacy of sitagliptin: subanalysis of the Januvia multicenter prospective trial in type 2 diabetes study. J Diabetes Investig. 2018;9(5):1159-66. https://doi.org/10. $1111 /$ jdi.12817

39. Takai M, Ishikawa M, Maeda $\mathrm{H}$, et al. A study of seasonal variation in the effect of add-on sitagliptin on blood glucose control in insulin-treated patients with type 2 diabetes. J Clin Med Res. 2020;12(3):200-8. https://doi.org/10.14740/jocmr4103

Publisher's Note Springer Nature remains neutral with regard to jurisdictional claims in published maps and institutional affiliations. 